\title{
Editorial: Despite COVID-19, Pharmaceutical Innovation Marches On!
}

\section{Stephen Scypinski ${ }^{1}$}

Published online: 13 August 2020

(C) Springer Science+Business Media, LLC, part of Springer Nature 2020

Dear readers of the Journal of Pharmaceutical Innovation:

Before I write my own editorial, I want to thank Wilson Meng and his other guest editors for their superb thematic edition in June on the development of biotherapeutics. Very well done Wilson!

Wow! Who would have thought just a few months ago how our world would change so dramatically? We are all experiencing new ways of working, both from an industrial as well as academic perspective.

But scientific innovation continues. Indeed, I have been amazed at the abundance of new manuscripts submitted to the Journal of Pharmaceutical Innovation since March of this year. Perhaps academic and industrial staff forced to work remotely have had a chance to pore over scientific notebooks and data and finally had a chance to write that manuscript they had put off due to other priorities.

The September issue of the Journal of Pharmaceutical Innovation is a good example of this vast assortment of new ideas and approaches to addressing the abundance of challenges that confront us every day in pharmaceutical development. The papers in this issue discuss practical as well as theoretical considerations for solving problems in pharmaceutical development and offer many innovative approaches. As I stated in my first editorial this year, we are always looking for new ideas and offers for scientists to review manuscripts. You can write to me anytime at sscypinski@ comcast.net.

This journal is growing and gaining notoriety. Thank you once again for your support.

\section{Compliance with Ethical Standards}

Disclaimer The statements contained herein are my personal views, opinions, and statements and not those of my employer.

Publisher's Note Springer Nature remains neutral with regard to jurisdictional claims in published maps and institutional affiliations.

Stephen Scypinski

1 Pharmaceutical Technology, Daichi-Sankyo Inc., Basking Ridge, NJ, USA 